\title{
The Analysis of Missing Cases on the Treatment of Rifampicin-Resistant Tuberculosis
}

\author{
Oster Suriani Simarmata ${ }^{*}$, Dina Bisara Lolong1, Kristina L Tobing ${ }^{1}$, \\ Nikson Sitorus ${ }^{1}$, Novianti ${ }^{1}$, Ina Kusrini ${ }^{2}$, Dian Perwitasari ${ }^{1}$, Lamria \\ Pangaribuan ${ }^{1}$, ${ }^{1}$ Researcher of National Institute of Health Research \\ Development (NIHRD), Ministry of Health, Indonesia, ${ }^{2}$ Researcher of National \\ Institute of Health Research and Development (NIHRD), Unit in Magelang, \\ Ministry of Health, Email: *oster_suriani@yahoo.com
}

To describe the follow-up treatment of Resistant Rifampicin in health care facilities based on the results of the gene-Xpert examination. The study design was cross-sectional using data from "Evaluation study of detection of TB cases with the rapid molecular test in Indonesia in 2018". The data resources were from 42 hospitals and two primary health care facilities having conducted the geneXpert examination at least six months in 42 districts, 26 provinces in Indonesia. The number of TB diagnoses with gene-Xpert from health facilities was 33,630 cases, $31.6 \%$ of those cases were TB positive, namely rifampicin sensitivity of $89 \%(9,456)$ and rifampicin-resistant of $11 \%$ (1,171). $29 \%$ of resistant rifampicin tuberculosis cases were missing cases consisting of the untreated and unknown follow-up treatment of $18 \%$ and $11 \%$, respectively. Missing cases were mostly found in males of $66.1 \%$. Based on the age, $76.9 \%$ of the missing cases were in productive age, such as 15 to 54 years. Moreover, according to the TB treatment history and origin of the case, missing cases were found in new cases, $54.4 \%$, and the existing health facility $51.2 \%$. The most reason for missing the RR-TB case in the follow-up treatment was the refusal of treatment $40.3 \%$. The high non-compliance to TB treatment was caused by inadequate general knowledge about TB, lack of social support, medication side effects, and long treatment period, which were posed as barriers to adherence to treatment.

Key words: Missing cases, Rifampicin resistant, Tuberculosis 


\section{INTRODUCTION}

Tuberculosis (TB) causes tremendous suffering worldwide, especially in low and middleincome countries such as Indonesia. Globally, in 2018, an estimated 10.0 million (range, 9.011.1 million) people have developed TB disease (active TB) for the first time, and over 1.2 million (range, 1.1-1.3 million) people have died from TB. Most people could be cured of TB if the disease is diagnosed and properly treated. One of the problems in treating TB is that the bacteria become resistant to antibiotics. Detecting TB and TB drug resistance earlier is vital for improving health, reducing deaths, and decreasing the spread of TB in communities (WHO, 2019).

The Xpert MTB/RIF is a new test that quickly detects TB and rifampicin resistance simultaneously. Rifampicin is an essential drug for treating people with TB. Since the test is automated, it does not require expert staff or an advanced laboratory. The Xpert MTB/RIF is an automated polymerase chain reaction (PCR) test (molecular test) using the GeneXpert. A single test can detect both $\mathrm{M}$. tuberculosis complex and rifampicin resistance with excellent accuracy and achieve early diagnosis within two hours after starting the test, with minimal hands-on technical time(Boehme et al., 2011; Nicol, Whitelaw, \& Stevens, 2013).

Steingart KR et al. conducted a meta-analysis based on some articles to compare the sensitivity of Xpert MTB/RIF to that of smear microscopy, the test commonly used for TB diagnosis in low- and middle-income countries. Smear microscopy is low-cost and fairly easy to do but requires trained staff and is a hassle for patients, who must provide at least two sputum samples. Also, microscopy gives no information about drug resistance. For TB detection, Xpert MTB/RIF was accurate, it was highly sensitive: $89 \%$ (85-92\%), detecting almost all cases, and specific: $99 \%$ (98\% to $99 \%$ ); compared to microscopy, with sensitivity of $67 \%$ (60\% to $74 \%$ ) and pooled specificity of $99 \%$ (98\% to $99 \%$ ). The overall sensitivity for rifampicin resistance was $95 \%$ (90\% to 97\%) on 17 studies and the overall specificity was $98 \%$ (97\% to 99\%) on 24 studies( $\mathrm{Kr}$ et al., 2015).

WHO reported that around $3.5 \%$ and $18 \%$ of MDR-TB/RR-TB were new cases and previously treated cases, respectively. India, China, and the Russian Federation accounted for $45 \%$ of these cases. Extensively drug-resistant TB (XDR-TB) is defined as MDR-TB with resistance to any fluoroquinolones and at least one of the second line injectables - amikacin, capreomycin, kanamycin. It accounts for 7.4\% of MDR-TB worldwide(WHO, 2018).

Therefore, the World Health Organization (WHO) issued initial recommendations on Xpert MTB/RIF in early 2011. Early detection is essential to reduce the death rate and interrupt transmission(WHO, 2011). Afterward, in 2016, the Regulation of the Minister of Health No. 67 of 2016 was issued, which mentions that one of the tools used for TB case diagnosis is the rapid molecular test Xpert MTB/RIF(Kementrian Kesehatan RI, 2016). The results of the Inventory Study is known that the underreporting rate of the incidence rate is $41 \%$ based on 
the recording at NTPs(Enarson, 1991).This study will analyze more specifically at missing cases in rifampicin-resistant tuberculosis treatment, which is assumed to be part of underreporting.

\section{MATERIAL AND METHOD}

The study method was cross-sectional carried out in 44 health facilities (42 hospitals and two health centers) in 42 districts/cities in 26 provinces in Indonesia.

Sampling is a probability sampling method by stratified random sampling. The first stage of stratification was based on identifying districts/cities whose GeneXpert MTB/RIF tools have been operated for six months and have been grouped into underdeveloped and not left behind areas. The second stage was to classify the regions based on fiscal capacity grouping, namely high / very high, medium, and low fiscal at each area. Therefore, the next six regional groups were selected in the district/city by the random system. Data collection methods were quantitative and qualitative. Quantitative data consists of primary data and secondary data. Primary data is the result of interviews with health care facilities regarding input, process, and output indicators to describe the management of Xpert MTB/RIF implementation, while secondary data is the detection of TB cases using Xpert MTB/RIF.

In 2018, the National Health Institute Research and Development conducted a study to evaluate the use of Rapid Molecular Test (RMT) with Xpert MTB/ RIF. This analysis focuses on analyzing secondary data on TB examination with Xpert MTB/RIF obtained from the 44 health service facilities in the 2014-July 2018 period. Demographic characteristics data, TB examination results with Xpert MTB/RIF test were analyzed descriptively with SPSS 17.

Xpert MTB/RIF test results were defined as negative TB if bacteriological confirmation was negative. Sensitive rifampicin if bacteriological confirmation was positive TB as sensitive to rifampicin. Resistant rifampicin if bacteriological confirmation was positive $\mathrm{TB}$ as resistance to rifampicin and indeterminate rifampicin if bacteriological confirmation was positive as indeterminate to rifampicin. Based on the results of this study, further analysis was carried out on Missing Cases on the Treatment of Rifampicin-Resistant Tuberculosis.

\section{RESULTS}

The data below are the results of univariate analysis sourced from 44 health service facilities that were the research samples. 
International Journal of Innovation, Creativity and Change. www.ijicc.net

Volume 15, Issue 9, 2021

Table 1. Results of TB Diagnostic Testing Using Xpert MTB/RIF on 44 Health Facilities in Indonesia, Period 2014 to July 2018

\begin{tabular}{|c|c|c|}
\hline Result & Frequency & Percentage \\
\hline Negative & 22,510 & 66.9 \\
\hline TB Positive: & 10,627 & 31.6 \\
\hline - Rif Sensitive & 9,456 & 89.0 \\
\hline - Rif Resistant & 1,171 & 11.0 \\
\hline Rif Indeterminate & 94 & 0.3 \\
\hline Invalid & 161 & 0.5 \\
\hline Error & 207 & 0.6 \\
\hline No Result & 31 & 0.1 \\
\hline Total & 33,630 & 100.0 \\
\hline
\end{tabular}

Source: RMT Survey Report (modified)

In table 1, the result of the analysis showed that the number of TB diagnostic tests using Xpert MTB/RIF which were collected from the health facilities were 33,630. 31.6\% of those cases were TB positive, comprised of $89 \%(9,456)$ rifampicin sensitive and $11 \%(1,171)$ rifampicin resistant.

Figure 1. Percentage of Follow-Up of Rifampicin-Resistant TB Treatment on 44 Health Facilities, Period 2014 to July 2018

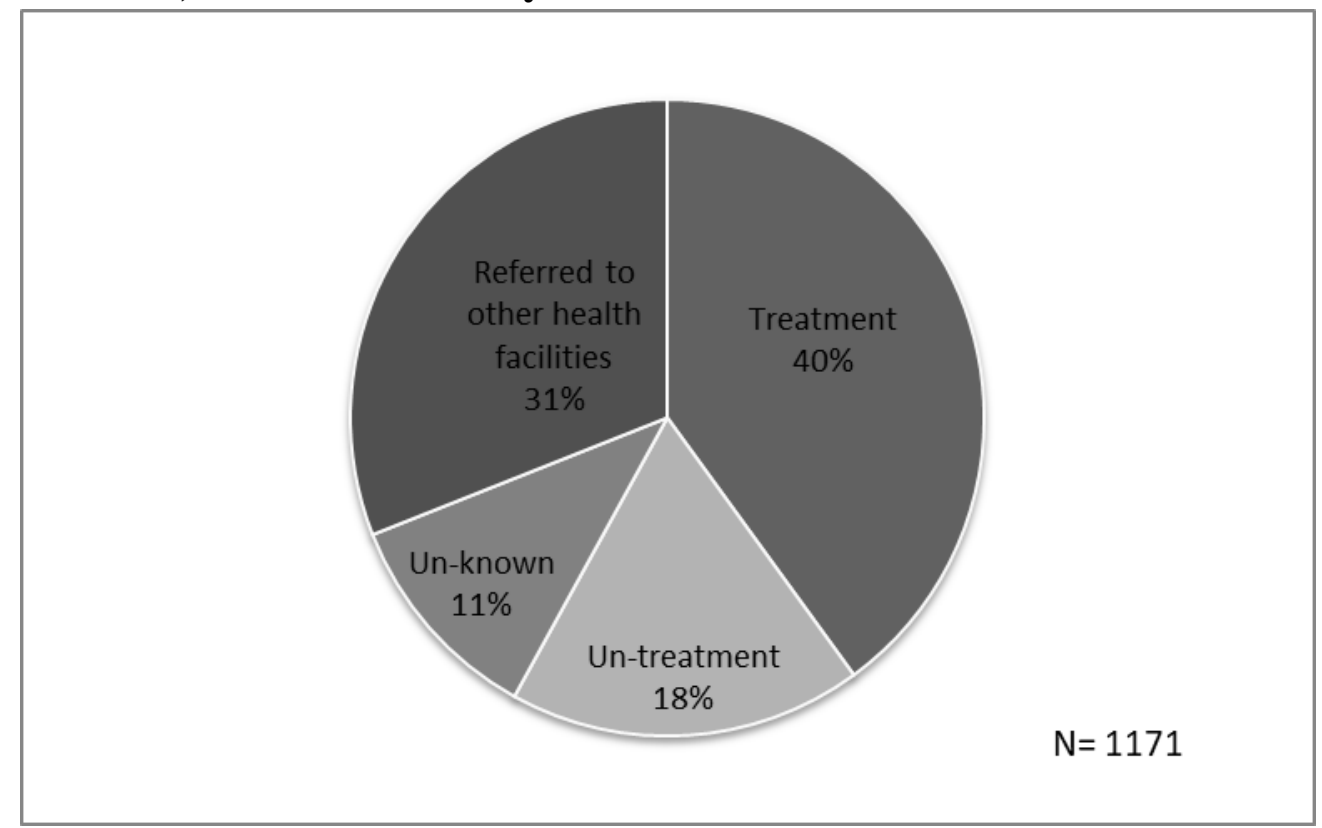

Source: RMT Survey Report

In Figure 1, the follow-up of 1,171 cases of rifampicin-resistant TB treatment revealed that $40 \%$ of the cases were directly taken care of by the health facility involved (existing health 
International Journal of Innovation, Creativity and Change. www.ijicc.net

Volume 15, Issue 9, 2021

facility), $31 \%$ were referred to another health facility and $29 \%$ turned out to be missing cases, consisted of $11 \%$ cases with unknown treatment follow-up status and $18 \%$ untreated cases.

Table 2. Untreated RR-TB Cases and RR-TB Cases with Unknown Treatment Follow-up Status According to Patient Characteristics on 44 Health Facilities, Period 2014 to July 2018

\begin{tabular}{|c|c|c|c|c|c|c|c|}
\hline \multirow{3}{*}{\multicolumn{2}{|c|}{ Patient Characteristics }} & \multicolumn{6}{|c|}{ Unknown } \\
\hline & & \multicolumn{2}{|c|}{ Untreated } & \multicolumn{2}{|c|}{$\begin{array}{l}\text { Treatment Follow- } \\
\text { up Status }\end{array}$} & \multicolumn{2}{|c|}{ Total } \\
\hline & & $\mathbf{n}$ & $\%$ & $\mathbf{n}$ & $\%$ & $\mathbf{n}$ & $\%$ \\
\hline \multicolumn{8}{|l|}{ Gender: } \\
\hline Male & & 144 & 68.2 & 82 & 62.6 & 226 & 66.1 \\
\hline Female & & 67 & 31.8 & 49 & 37.4 & 116 & 33.9 \\
\hline \multicolumn{8}{|l|}{ Age: } \\
\hline$<15$ years & & 2 & 0.9 & 3 & 2.3 & 5 & 1.5 \\
\hline $15-54$ years & & 160 & 75.8 & 103 & 78.6 & 263 & 76.9 \\
\hline$>=55$ years & & 49 & 23.2 & 25 & 18.8 & 74 & 21.6 \\
\hline \multicolumn{8}{|l|}{ TB Treatment History: } \\
\hline New Case & & 97 & 46.1 & 89 & 67.9 & 186 & 54.4 \\
\hline Recurrent Case & & 114 & 54.0 & 42 & 32.1 & 156 & 45.6 \\
\hline \multicolumn{8}{|l|}{ Origin of Case: } \\
\hline Existing Health Facility & & 126 & 59.7 & 49 & 37.4 & 175 & 51.2 \\
\hline $\begin{array}{l}\text { Referred from Public } \\
\text { Centers }\end{array}$ & Health & 38 & 18.0 & 43 & 32.2 & 81 & 23.7 \\
\hline Referred from Hospitals & & 36 & 17.1 & 13 & 9.9 & 49 & 14.3 \\
\hline $\begin{array}{l}\text { Referred from } \\
\text { Practitioners/Clinics }\end{array}$ & Private & 11 & 5.2 & 8 & 6.1 & 19 & 5.6 \\
\hline Unknown & & 0 & 0.0 & 18 & 13.7 & 18 & 5.3 \\
\hline Total & & 211 & 100.0 & 133 & 100.0 & 342 & 100.0 \\
\hline
\end{tabular}

In table 2, the missing cases of rifampicin-resistant TB shown in Table 2 that included untreated cases and cases with unknown treatment follow-up status were found mostly in males $(66.1 \%)$ and of the productive age group (15-54 years) $(76.9 \%)$. Based on TB treatment history, missing cases were found to be high in new cases, which was $54.4 \%$. Based on the origin of the case, missing cases were higher in patients from the existing health facility $(51.2 \%)$, followed by patients referred from public health facilities known as puskesmas $(23.7 \%)$ and patients referred from hospitals (14.3\%). 
International Journal of Innovation, Creativity and Change. www.ijicc.net

Volume 15, Issue 9, 2021

Table 3. The Reasons for Missing RR-TB Case in the Follow-up Treatment

\begin{tabular}{|c|c|c|}
\hline The Reasons & $\mathbf{n}$ & $\%$ \\
\hline Refusal of treatment & 85 & 40.3 \\
\hline Patient escaped & 30 & 14.2 \\
\hline Death & 22 & 10.4 \\
\hline Death before treatment & 19 & 9.0 \\
\hline Waiting for treatment & 19 & 9.0 \\
\hline Anti-TB drugs out of stock, the patient did not return & 3 & 1.4 \\
\hline Unknown reasons & 33 & 15.6 \\
\hline Total & 211 & 100.0 \\
\hline
\end{tabular}

Table 3 revealed that half $(54.5 \%)$ the reasons patients were not treated came from patient's behavior, which was the patient's refusal to be treated (40.3\%) and escape (14.2\%). Another reason was the patient's death (19.4\%) before or during treatment $(10.4 \%$; $9.0 \%)$. Meanwhile, in terms of the preparedness of health facilities to provide care, the reasons for the untreated cases included the fact that patients had to wait for treatment $(9.0 \%)$ and also the unavailability of anti-TB drugs (out of stock) at the facility resulting in patients not returning for treatment $(1.4 \%)$. From the availability of data, $15.6 \%$ of data was discovered to be incomplete, so the reasons for untreated cases were unknown.

\section{DISCUSSION}

Many of the critical principles of tuberculosis (TB) control are to develop a set of registries to capture information on patients evaluated for TB and then use the registries to monitor and evaluate the performance of early TB control programs. According to Dr. Karel Styblo, the most crucial step is the organization of the primary components of the National Tuberculosis Programme. This first step requires such as a political commitment on the part of the Government, a secure supply of drugs and materials, including a reserve stock, a network of microscopy centers with a system of quality control and proper recording and reporting of cases(Kementrian Kesehatan RI, 2011).

The Indonesia National TB control program has a standardized recording and reporting system, which is the basis for developing TB information systems. At the health service facility level, the standard recording format is used. At the district/city and provincial levels, the TB program manager (Wasor=wakil koordinator TB) has used an electronic TB software that aims to facilitate data management for the completion of quarterly case finding reports, conversion results, and TB treatment outcomes(Kementrian Kesehatan RI, 2014). Even though the system already developed, the 2013 -2014 Indonesian national TB prevalence survey indicated that two-thirds of treated TB patients were not reported to the NTP(WHO, 2019) [11]. Based on WHO data, many unreported TB cases were reaching up to 4 million $(40 \%)$ TB patients out of 10,000,000 incident cases(Kemenkes, 2018). 
This data is similar to the data from the Indonesia Inventory Study which reported that underreporting of TB cases (not reported to NTPs) each year was $41 \%$ of all incident cases. This result is in line with the Indonesia Inventory Study recent report that there remains a gap namely $59 \%$ (41\% under-reporting and 18\% undetected) between TB incidence (842,000 cases) and the number of new cases diagnosed in Indonesia, 2017(Enarson, 1991). These "missing" patients are either undiagnosed or are diagnosed but not reported. We should prioritize finding these patients and linking them to effective treatment(Ehsanul Huq et al., 2018; WHO, 2016).

This recent study revealed that as many as 10,627.08 (31,6\%) out of 33,630 cases tested were MTB positive, then 1171 (11\%) out of 10,627.08 were rifampicin-resistant. Meanwhile, from the rifampicin-resistant cases diagnosed, $18 \%$ (211) were not treated, and 11\% (129) cases were not known. So, the total number of missing TB rifampicin-resistant cases were 340 cases in 2017.

RSUP Dr. Moh. Hoesin Palembang 2019 reported using GeneXpert MTB/RIF to detect rifampicin-resistant Mycobacterium tuberculosis from pulmonary TB patients in the hospital. They found that the sensitivity and specificity of the Xpert test were $97 \%$ and $93 \%$ respectively. The prevalence of rifampicin resistance was 5.9\%(WHO, 2016), comprising 5\% of the total global TB burden(Erizka Rivani, Tia Sabrina, 2019).

After the results of the meta-analysis above, the detection of Mycobacterium tuberculosis in sputum samples from suspected pulmonary tuberculosis patients has been significantly improved by the Xpert MTB/RIF. This essay seems to be predetermined for use with specimens other than sputum as well, such as cerebrospinal fluid or effusions from various sites including pleural effusion. Friedrich et al. (2011) in South Africa investigated the diagnostic utility of the Xpert MTB/RIF in 20 cases with confirmed tuberculous pleural effusion. The sensitivity and specificity of the Xpert assay in pleural fluid were $25 \%$ and $100 \%$, respectively. All cases positive by the Xpert assay were also positive by the pleural fluid culture(Friedrich, Von Groote-Bidlingmaier, \& Diacon, 2011). In addition, in Northeast Ethiopia (2018), an examination of extrapulmonary tuberculosis among 353 presumptive TB was carried out including TB lymphadenitis, pleural, and peritoneal TB specimens using Gene Xpert MTB/RIF assay and fluorescent microscopy. They found that from a total of 353 presumptive EPTB cases, the overall prevalence of Gene Xpert assay and smear confirmed patients were $8.8 \%$ and $2.5 \%$, respectively. Tuberculosis lymphadenitis was the predominant $(33.3 \%)$ type followed by pleural (11.9\%) and peritoneal $(6.7 \%)$ tuberculosis(Metaferia, Seid, Fenta, \& Gebretsadik, 2018).

Besides its effect on patients, weakness in diagnosing and rapid treatment can also have an impact on the development of secondary resistance and the spread of this disease. In this situation, not only the rapid detection of TB cases but also knowing the status of MDR in advance is a significant factor. The conventional diagnosis of pulmonary TB has a lower 
sensitivity and specificity compared to culture(Rifat, Hall, Oldmeadow, Husain, \& Milton, 2015).

Adherence to TB treatment is crucial to avert disease infectiousness, achieve a cure, and avoid the emergence of drug resistance, relapse, and death. Non-adherence to TB treatment is an important barrier and one of the most significant obstacles to TB control globally. It has become a major contributing factor to treatment failure(De Schacht et al., 2019; J. Dick, 1997).

Poor medication adherence among tuberculosis (TB) patients contributes not only to the worsening of their TB situation but also paves the way for the incidence of drug resistance. Most studies show that many hindering factors influence TB patients' adherence to treatment. A study in Eritrea (2018) reported that some the factors empirically were shown to affect drug adherence included lack of knowledge about TB in general and about treatment regimen and length in particular - even almost half of the respondents did not know the standard treatment duration and the consequences they face if they halt treatment, loss of employment(Gebreweld et al., 2018)or the opportunity to work and subsequent financial difficulties, transport problems and lack of access to health services, social stigma and discrimination, medication side effects, long treatment period, inadequate food, and poor communication with service providers (Gele, Sagbakken, Abebe, \& Bjune, 2010; Gugssa, Shimels, \& Bilal, 2017). Furthermore, TB stigma and the fact that many people still believe that TB was caused by magic also contribute to nonadherence to TB treatment(Gebreweld et al., 2018), including in Indonesia(I, 2018).

The most critical barrier for treatment is the transportation barrier, which is also faced by Indonesia with its thousands of islands. Patients with rifampicin-resistant TB should rest in the hospital at least in the first two weeks. In Argentina, an increased risk of non-adherence with treatment was found in patients who had medical check-ups at hospitals those who had difficulties with transportation costs(Herrero, Ramos, \& Arrossi, 2015). The prolonged duration of TB treatment affects patients' adherence due to their daily routine activities. This causes challenges for the patients and their families because it exhausts them financially, physically, and psychologically(Dueñes \& Cardona, 2016).

The other approach is the patient pathway analysis (PPA). The PPA begins where TB patients initiate care. Patient behavior and care are assessed at various points along the care-seeking pathway until the end of treatment. The analysis utilizes available population-based surveys to determine the degree of alignment between where patients initiate care, where TB services are available, and where patients are diagnosed or treated. The higher the misalignment between the location of care initiation and the availability of diagnostic and treatment services, the higher the likelihood that patients will drop out during the process of diagnosis and treatment. PPA, therefore, provides valuable information on why there are "missing" cases(Hanson, Osberg, Brown, Durham, \& Chin, 2017). 
International Journal of Innovation, Creativity and Change. www.ijicc.net

Volume 15, Issue 9, 2021

\section{CONCLUSION}

This study showed that the high non-compliance to TB treatment was caused by inadequate general knowledge about TB, lack of social support, medication side effects, and long treatment period, which were posed as barriers to adherence to treatment. The short distance to reach health facilities as Puskesmas (public health centers) is necessary for closer to the community for treatment starting from diagnosis until finishing treatment. It is crucial to comprehensive health education at treatment sites patient's family members and the community at large for better treatment adherence. Also, the strengthening of social support structures needs to be addressed.

\section{LIMITATIONS}

This study used secondary data, which was collected from registration data provided by health facilities. The completeness of the registration data was various, which started from complete to incomplete data.

\section{ETHICS STATEMENT}

Study to Evaluate the Use of Rapid Molecular Test (RMT) with Xpert MTB/ RIF was approved by the ethics committee of the National Institute of Health Research and Development.

\section{CONFLICT OF INTEREST}

The authors have no conflicts of interest associated with the material presented in this paper.

\section{AUTHOR CONTRIBUTIONS}

Conceptualization: OSS, DBL, KLT. Data collection: OSS, DBL, KLT, NS, N. Formal analysis: OSS, KLT. Funding acquisition: None. Writing-original draft: OSS. Writing-review \& editing: DBL, KLT, NK, N, IK, DP, LP. Submission: OSS, IK.

\section{ACKNOWLEDGMENT}

We want to express our gratitude to all NIHRD researchers and NTP staff who contributed to developing the protocol until finalizing the results; and National and Provincial/ District level Health staff for helping field activities. We also gratefully acknowledge WHO consultants and KNCV staff who had provided technical assistance support for this study. 
International Journal of Innovation, Creativity and Change. www.ijicc.net

Volume 15, Issue 9, 2021

\section{REFERENCES}

Boehme, C. C., Nicol, M. P., Nabeta, P., Michael, J. S., Gotuzzo, E., Tahirli, R., .. Perkins, M. D. (2011). Feasibility, diagnostic accuracy, and effectiveness of decentralised use of the Xpert MTB/RIF test for diagnosis of tuberculosis and multidrug resistance: A multicentre implementation study. The Lancet, 377(9776), 1495-1505. https://doi.org/10.1016/S0140-6736(11)60438-8

De Schacht, C., Mutaquiha, C., Faria, F., Castro, G., Manaca, N., Manhiça, I., \& Cowan, J. (2019). Barriers to access and adherence to tuberculosis services, as perceived by patients: A qualitative study in Mozambique. Plos One, 14(7), e0219470. https://doi.org/10.1371/journal.pone.0219470

Dueñes, M., \& Cardona, D. (2016). Factores relacionados con la adherencia al tratamiento en pacientes con tuberculosis. Pereira, Colombia 2012-2013. Biomédica, 36(3). https://doi.org/10.7705/biomedica.v36i3.2904

Ehsanul Huq, K. A. T. M., Moriyama, M., Zaman, K., Chisti, M. J., Long, J., Islam, A., ... Rahman, M. M. (2018). Health seeking behaviour and delayed management of tuberculosis patients in rural Bangladesh 11 Medical and Health Sciences 1117 Public Health and Health Services. BMC Infectious Diseases, 18(1), 1-9. https://doi.org/10.1186/s12879-018-3430-0

Enarson, D. A. (1991). Principles of IUATLD collaborative tuberculosis progammes. Bulletin of the International Union Against Tuberculosis and Lung Disease, Vol. 66, pp. 195200.

Erizka Rivani, Tia Sabrina, V. P. (2019). Perbandingan uji diagnostik GeneXpert MTB / RIF untuk mendeteksi resistensi rifampicin Mycobacterium tuberculosis pada pasien $\mathrm{Tb}$ paru di RSUP dr. Moh. Hoesin Palembang. JKK, 6(1), 23-28.

Friedrich, S. O., Von Groote-Bidlingmaier, F., \& Diacon, A. H. (2011). Xpert MTB/RIF assay for diagnosis of pleural tuberculosis. Journal of Clinical Microbiology, 49(12), 43414342. https://doi.org/10.1128/JCM.05454-11

Gebreweld, F. H., Kifle, M. M., Gebremicheal, F. E., Simel, L. L., Gezae, M. M., Ghebreyesus, S. S., ... Wahd, N. G. (2018). Factors influencing adherence to tuberculosis treatment in Asmara, Eritrea: A qualitative study. Journal of Health, Population and Nutrition, 37(1), 1-9. https://doi.org/10.1186/s41043-017-0132-y

Gele, A. A., Sagbakken, M., Abebe, F., \& Bjune, G. A. (2010). Barriers to tuberculosis care : a qualitative study among Somali pastoralists in Ethiopia. BMC, 3, 86.

Gugssa, C., Shimels, T., \& Bilal, A. I. (2017). Factors contributing to non-adherence with treatment among TBpatients in Sodo Woreda, Gurage Zone, Southern Ethiopia: Aqualitative study qualitative study. Journal of Infection and Public Health, 10(5), 527533. https://doi.org/10.1016/j.jiph.2016.11.018

Hanson, C. L., Osberg, M., Brown, J., Durham, G., \& Chin, D. P. (2017). Conducting PatientPathway Analysis to Inform Programming of Tuberculosis Services: Methods. Journal 
International Journal of Innovation, Creativity and Change. www.ijicc.net

Volume 15, Issue 9, 2021

of Infectious Diseases, 216(Suppl 7), S679-S685. https://doi.org/10.1093/infdis/jix387

Herrero, M. B., Ramos, S., \& Arrossi, S. (2015). Determinantes da não adesão ao tratamento da tuberculose na argentina: Barreiras relacionadas com o acesso ao tratamento. Revista Brasileira de Epidemiologia, 18(2), 287-298. https://doi.org/10.1590/19805497201500020001

I, K. K. R. (2018). Evaluasi Tes Cepat Molekules TB di Indonesia.

J. Dick, C. L. (1997). Shared vision a health education project designed to enhance adherence to anti tuberculosis treatment. INT J TUBERC LUNG DIS, 1, 181-186.

Kemenkes. (2018). Inventory StudyTuberculocis in Indonesia 2016-2017. https://doi.org/978602-373-117

Kementerian Kessehatan. (2014). Laporan Survei Prevalensi TB Indonesia 2013-2014.

Kementrian Kesehatan RI. Pedoman nasional Pengendalian Tuberculosis tahun 2011. , (2011).

Kementrian Kesehatan RI. (2014). Laporan Survei Prevalensi Tuberculosis Indonesia 20132014.

Kementrian Kesehatan RI. Peraturan Menteri Kesehatan no 67 tahun 2016. , (2016).

Kr, Steingart, Schiller, I., Dj, H., Pai, M., Cc, B., \& Dendukuri, N. (2015). Xpert ® MTB / RIF assay for pulmonary tuberculosis and rifampicin resistance in adults (Review). Cochrane Database of Systematic Reviews, (1), 1-167. https://doi.org/10.1002/14651858.CD009593.pub3.www.cochranelibrary.com

Metaferia, Y., Seid, A., Fenta, G. M., \& Gebretsadik, D. (2018). Assessment of Extrapulmonary Tuberculosis Using Gene Xpert MTB/RIF Assay and Fluorescent Microscopy and Its Risk Factors at Dessie Referral Hospital, Northeast Ethiopia. BioMed Research International, 2018. https://doi.org/10.1155/2018/8207098

Nicol, M. P., Whitelaw, A., \& Stevens, W. (2013). Using Xpert MTB / RIF. Current Respiratory Medicine, 9(3), 187-192.

Rifat, M., Hall, J., Oldmeadow, C., Husain, A., \& Milton, A. H. (2015). Health system delay in treatment of multidrug resistant tuberculosis patients in Bangladesh. BMC Infectious Diseases, 15(1), 1-8. https://doi.org/10.1186/s12879-015-1253-9

WHO. (2011). Automated Real-time Nucleic Acid Amplification Technology for Rapid and Simultaneous Detection of Tuberculosis and Rifampicin Resistance : Xpert MTB / RIF System. WHO.

WHO. (2016). Global Tuberculosis Report 2016.

WHO. (2018). Global Tuberculosis Report.

WHO. (2019). Global Tuberculosis Report 2019. In WHO. 